\title{
GUERRA BIOPOLÍTICA E CRISE DE REPRESENTAÇÃO DEMOCRÁTICA NA COPA DO MUNDO 2014
}

\author{
André Luiz Maranhão de Souza Leâo \\ Universidade Federal de Pernambuco, Brasil \\ aleao21@hotmail.com \\ Sérgio Luiz Elias de Araújo \\ Universidade Federal de Sergipe, Brasil \\ sergioaraujo@sergioaraujo.com.br \\ Bruno Rafael Torres Ferreira \\ Universidade Federal de Pernambuco, Brasil \\ brunortferreira@gmail.com \\ Bruno Melo Moura \\ Universidade Federal de Pernambuco, Brasil \\ brunomtop@gmail.com
}

\section{RESUMEN}

Los organizadores de la Copa del Mundo de 2014 prometieron que ella generaría beneficios para Brasil. Sin embargo, esta promesa generó incredulidad y protestas por parte de la sociedad brasileña. A partir de una comprensión del endurecimiento de estas diferentes posiciones como un conflicto de interés en torno a las prácticas y sistemas de control de la vida, este artículo analiza la guerra biopolítica desarrollada lo largo de la organización de la Copa del Mundo de Brasil. Basado en la teoría política de Hardt y Negri y el Análisis del Discurso de Foucault como un método, el trabajo analiza un conjunto de 776 documentos. Ellos revelan, por un lado, un intento del gobierno por controlar la opinión pública. Por otra parte, el artículo muestra el desarrollo de una resistencia de la sociedad a esa acción gubernamental. Esta dinámica revela cómo la Copa del Mundo de 2014 ha jugado un papel en la crisis democrática brasileña actual.

Palabras clave: Copa del Mundo de la FIFA, Biopolítica, Democracia, Participación, Brasil. 


\title{
BIOPOLITICAL WAR AND THE CRISIS OF DEMOCRATIC REPRESENTATION IN THE 2014 WORLD CUP
}

\begin{abstract}
The organizers of the 2014 World Cup promised that it would generate benefits for Brazil. However, this promise was met with incredulity and protests on the part of Brazilian society. Starting from an understanding of the hardening of these different positions as a conflict of interests around the practices and systems of control of life, this article analyzes the biopolitical war that ensued throughout the organization of the Brazil World Cup. Based on the political theory of Hardt and Negri and the method of Foucault's Discourse Analysis, this study analyzes a set of 779 documents. These reveal, on the one hand, an attempt by the government to control public opinion. On the other hand, the article shows the development of a resistance of society to this government action. This dynamic reveals how the 2014 World Cup has played a role in Brazil's current democratic crisis.
\end{abstract}

Keywords: FIFA World Cup, Biopolitics, Democracy, Participation, Brazil. 


\section{INTRODUÇÃO}

Principal evento promovido pela Fédération Internationale de Football Association (FIFA), a Copa do Mundo de Futebol é realizada a cada quatro anos em um país e conta com a presença de 31 seleçóes, além do paíssede (FIFA 2013). A organizaçáo do evento no Brasil contou com dois agentes importantes: de um lado, o Governo Federal, representado pela presença do Comitê Gestor da Copa do Mundo FIFA 2014 (CGCOPA) e o do Grupo Executivo da Copa do Mundo FIFA 2014 (GECOPA), responsáveis pela coordenação e execução de açóes e obras voltadas para a realização do evento (Decreto de 14 de janeiro de 2010); e, do outro lado, a FIFA, através do Comitê Organizador Local da Copa (COL), entidade que atuava em paralelo à presença da Confederação Brasileira de Futebol (CBF). Neste cenário, as 12 cidades escolhidas para sediar jogos da Copa do Mundo passaram obras de Com a presença de tais agentes, as 12 cidadessedes escolhidas foram alvos de açôes, obras e políticas e em torno das áreas de telecomunicaçôes, segurança, infraestrutura e mobilidade, executadas e financiadas a partir de recursos públicos e privados (Resolução 21, 22 de novembro de 2012).

Inserida neste contexto, a realização da Copa do Mundo trouxe promessas de legados, principalmente no que diz respeito à produção de uma imagem positiva do país no exterior e aos benefícios deixados para a população com a execução obras estruturais (Nicolas 2013); além de um legado esportivo, ilustrado pela possibilidade de uma nova relação entre torcedores e clubes (Grellet 2010) e a presença das novas arenas.

No entanto, foi possível acompanharmos uma série de conflitos envolvendo os dois agentes organizadores do evento. Além de cobranças públicas acerca dos atrasos de obras - principalmente daquelas ligadas aos estádios —, um dos principalmentes pontos de discussáo entre Governo Federal e FIFA ocorreram durante a elaboração da chamada Lei Geral de Copa (Lei. 12.663 de 5 de junho de 2012). Sancionada em junho de 2012, esta lei foi elaborada para determinar diretrizes importantes visando, assim, garantir a realização da Copa do Mundo e da Copa das Confederaçóes e o atendimento dos interesses das partes envolvidas (Resolução 21, 22 de novembro de 2012). A presença de interesses dissonantes esbarrou em leis antigas e locais, trazendo à tona discussóes entre aqueles que achavam legítima a criação de exceçôes a tais leis e aqueles que viam neste ponto uma afronta a soberania nacional. Em Pernambuco, por exemplo, onde a venda de bebidas alcoólicas é proibida desde 2009, houve por parte do Ministério Público estadual o interesse de preservar a determinação da lei estadual (Jornal do Commercio 2011), situação que ia de encontro como 
a Lei Geral da Copa, que liberava a venda de bebidas alcoólicas e que determina ser proibida a venda de produtos náo-licenciados nos entornos dos estádios, inibindo a ação de trabalhadores informais e obrigando estabelecimentos comerciais a vender produtos indicados da FIFA, o que causou a insatisfaçáo de comerciantes e órgáos de defesa do consumidor (Jornal do Commercio 2012).

Tais conflitos não aconteceram de forma velada e influenciou de forma negativa o modo como parcela da população viu a organização da Copa do Mundo e os impactos do megaevento em suas vidas. Apesar do esforço das duas frentes da organização de mostrar e incentivar a da população brasileira nos preparativos, através de açóes nos meios de comunicação visando o envolvimento da populaçáo - como fora a escolha do nome do mascote do Copa do Mundo (Uol 2012) —, a sociedade mostrou-se contrária em algumas situaçóes, manifestando-se a partir de blogs, nas redes sociais e, de forma mais significativa, em manifestaçóes públicas, como acontecera em 2013, ao longo da realização da Copa das Confederaçôes, competição que conta com a participação das seleçóes campeãs continentais e que serviu de teste para a organização.

Este cenário que descreve a presença da atuação das esferas governamentais e privadas — assim como da sociedade civil — na preparação e realização da Copa do Mundo no país revela não somente os conflitos de interesses entre os envolvidos, mas também os impactos nas vidas das pessoas, uma vez que graças às regras impostas pela FIFA no que diz respeito ao que deve (e não deve) ser feito durante sua atuação no país com a Copa do Mundo e às consequências direta e indiretas das modificaçóes sofridas no espaços urbanos pelas obras de infraestrutura o cotidiano das pessoas foi afetado, seja de forma temporária ou permanente. A ideia de transformação e controle da vida - como tal dinâmica descreve - está presente no conceito de biopolítica, e que Michael Hardt e Antonio Negri utilizam na teoria política do Império.

Argumentamos, assim, que a realização da Copa do Mundo no país pôde revelar - através dos posiçóes discursivas dos agentes envolvidos nos preparativos e da sociedade brasileira - a presença e os efeitos do que chamamos aqui de guerra biopolítica: o conflito de interesses entre instituiçôes em torno de práticas e sistemas de controle da vida. Com base nisto, nossa investigaçáo foi orientada pela seguinte pergunta de pesquisa: o que é revelado pela guerra biopolítica instaurada ao longo da organização da Copa do Mundo no Brasil?

$\mathrm{CV}$ 
Como justificativa para a realização dessa pesquisa, apontamos a importância do futebol na sociedade brasileira, aqui evidenciado pela realizaçáo da Copa do Mundo: embora seja considerado um simples esporte ou entretenimento por alguns, o futebol carrega em si aspectos sociais, culturais, políticos e econômicos de um grupo social (Da Matta 1991, Damo \& Oliven 2013), sendo o megaevento esportivo da FIFA responsável por impactos em diferentes segmentos da nação (Diniz, Ribeiro \& Palhares 2017, Nobre 2017, Reis \& Cabral 2017). No que diz respeito à justificativa acadêmica, o presente estudo nos permite observar a relação entre as açóes da gestão pública e o atendimento de demandas sociais, bem como a dinâmica entre agentes (públicos, privados e a sociedade civil) envolvidos na organização da Copa do Mundo no país sob o olhar de uma teoria política, como a elaborada por Michael Hardt e Antonio Negri.

\section{GESTÃO PÚBLICA E DEMOCRACIA}

Aspectos sociais e culturais de uma sociedade muitas vezes são geridos por órgãos públicos que devem alocar, de forma eficiente, recursos para atender às suas demandas. $\mathrm{Na}$ sociedade contemporânea, encontramos uma grande diversidade de atores negociando, influenciando e agindo sobre questóes públicas. Assim, não é mais tão simples diferenciar a fronteira entre a gestão pública e a privada; o Estado não é mais o único ator a regular o comportamento dos agentes sociais (Djelic \& Sahlin-Andersson 2006, Richard \& Rieu 2009), muito menos o único a desenvolver questôes sobre o que é público.

O modelo atual de gestão da administração pública surgiu como resposta à ineficiência burocrática, pois, ao introduzir, nas instituiçôes governamentais e públicas, dispositivos de gestão oriundos da administração de empresas, tornou-se evidente a premissa que o setor privado era mais eficiente que o setor público, principalmente quanto ao planejamento e manutenção de decisões administrativas (Oliveira \& Paula 2014). A nova forma de gerir as contas públicas estabeleceu como objetivo principal erradicar a crise fiscal, bem como o desempenho deficitário tanto na qualidade quanto na quantidade dos serviços ofertados pela administraçáo pública. Todavia, nem todos iriam servir, pois a administração pública detém características que não existem no setor privado (Denhardt \& Denhardt 2000). A principal delas é que a gestão pública é muito complexa, já que se foca, predominantemente, na eficiência do governo, acabando por se omitir na inclusão efetiva da dimensão sociopolítica quando um gestor público tenta colocar em prática as premissas do setor privado sem considerar que está contrariando a necessidade de negociaçáo entre o governo e a sociedade civil, já que sua posição é hegemônica, amparada por lei, quanto a ser o 
único detentor de alguns dos recursos (Paula 2005). Logo, seria válido que o Estado fosse devidamente conduzido de forma democrática e, para isso, seus cidadãos devem ter meios de participar do processo de definição e implantação de suas políticas públicas (Denhardt \& Denhardt 2000).

Tais elementos são alguns dos que tornam uma gestáo inovadora no setor público um grande desafio. A emergente necessidade por serviços públicos mais transparentes e democráticos requerem dos governos novos modelos de gestão, bem como novos procedimentos de planejamento e manutenção, tal qual formas de comunicação para com a sociedade, que os capacite para ofertar a resposta para a demanda desses serviços. Contudo, essa inovação é dificultada, não só pelas particularidades que que não podem ser importadas da administração privada, como também por ainda serem fortemente limitados por princípios da administração pública tradicional (Osborne \& Brown 2011, Amdam 2014).

O Novo Serviço Público surge como uma solução para a gestão pública (Abreu, Helou, \& Fialho 2013), pois, ao propor uma mudança no paradigma de uma gestáo que busque mais participação da sociedade, endossa o ideal da participação da sociedade nas formulações das políticas que irão geri-la, já que uma responsabilidade democrática tende a acarretar uma eficiência do serviço público (Klumb \& Hoffman 2016). Seus pressupostos promovem a dignidade e o valor do serviço público e reafirmam os valores da democracia do interesse público como proeminentes de uma gestão pública eficiente (Denhardt 2012). Os valores democráticos exprimidos na liderança e gestão dos órgáos públicos colocaram em xeque, segundo Denhardt (2012), os princípios da administração pública que, até então, eram hegemônicos. Assim, a concepção do Novo Serviço Público parece funcionar como ignição para a reformulação de como o Estado pode ser gerido de forma democrática, de modo que ocorra uma alteração no paradigma da busca de uma gestão mais participativa.

Contudo, qual seria a forma democrática de estabelecer essa gestáo participativa? Tenório (2005) define duas formas que usualmente são debatidas: a participativa e a representativa. A primeira se estabelece quando se verifica um relacionamento eficaz entre os cidadáos e o poder público na formulação de políticas que respondam diretamente às suas demandas. Já a representativa ocorre quando é observada uma distância entre a sociedade e a instituição que a governa, sendo as políticas públicas formuladas indiretamente. A participativa, segundo o autor, apesar de parecer mais eficiente, pouca valia tem em estados com populaçóes densas, já que seria inviável considerar a opiniâo de cada cidadão, sendo assim necessária a implementação da representativa nesses casos. 
Então, para o exercício da democracia, nas grandes cidades da atualidade, uma instituição democrática representativa é necessária. Porém, esta terá sua legitimidade comprometida de acordo com a o grau de apoio de seus cidadãos e o nível de satisfação com o seu funcionamento (Dahl 2001). Para manter um grau de apoio positivo, uma instituição democrática deve entender que, na atualidade, já não é mais o único ator a regular o comportamento dos agentes sociais, muito menos o único a desenvolver questóes sobre o que é público (Richard \& Rieu 2009). É vital que o Estado seja regido por regras que delimitem seu campo de atuação em prol da defesa de direitos básicos dos cidadáos, tanto individuais como coletivos, tanto que as eleiçóes se tornaram o principal instrumento de prestação de contas do governo aos cidadãos (Medeiros, Crantschaninov, \& Silva 2013). A inovação nos serviços ofertados por uma instituição pública pode incluir a produção de bens materiais ou produtos, que o força a disponibiliza também a entrega destes, bem como dos serviços relacionados e isso acaba por forçar mudanças organizacionais e no desenvolvimento de políticas (Koch \& Hauknes 2005), porém, tem sido mais frequente, que essas instituiçóes se foquem em ofertar produçóes imateriais que atendam às demandas momentâneas da sua sociedade.

\section{A BIOPOLÍTICA NA TEORIA POLÍTICA DE MICHAEL HARDT E ANTÔNIO NEGRI}

Na Teoria do Império (Hardt \& Negri 2006, 2012), Michael Hardt e Antônio Negri buscam explicar como se dá a nova ordem socioeconômica mundial que tem como base a ação de instituiçóes internacionais sobre totalidade do mundo que, como descrevem os autores, mostra-se configurada em um espaço sem fronteiras. Tal cenário é produto de um processo que teve início com a gradual transformação dos Estados-nação, que deixaram de ser unidades políticas hegemônicas e passaram a ser cenários da atuação de corporaçôes e dos efeitos da globalização, de modo a produzir contantes embates que envolvem a pressão de tais corporaçóes e instituiçôes sob a soberania local.

Nesta teoria política, um importante conceito, baseado na teoria social de Michel Foucault, é o de biopoder: uma forma de poder que regula a vida social do homem, a partir da administração das características e atividades humanas. Assim, o conjunto da sociedade está inserido no poder biopolítico, sendo que este é capaz de produzir o corpo social, e os nossos corpos individuais, sendo a essência de toda a produtividade. Enquanto que as disciplinas contam com instrumentos que produzem e regulam os costumes e práticas dos cidadãos, a biopolítica age como modos vivos e múltiplos de exercícios de atividades sociais, existentes na 
sociedade contemporânea, que diferem ou excedem aqueles formalmente reconhecidos nos moldes padronizados impostos pelo sistema capitalista moderno.

$\mathrm{Na}$ sociedade contemporânea neoliberal, os governos têm a responsabilidades de divulgar informaçóes verossímeis a serem compartilhadas com todos os seus atores econômicos racionais (Giesler \& Veresiu 2014, Lemke 2007). Quando estas são insuficientes ou dúbias, a sociedade se percebe num estado de guerra: se pronticam para um contrataque à iminência de evidências de possíveis ataques; sendo este estimulado por duas lógicas: a precaução e a agressividade, que levam as sociedades a se armar com aquilo que abominam (e.g. produzir armas biológicas para combater uma guerra biológica) (Collier \& Lakoff 2014, Cooper 2006).

Logo, a biopolítica é um mecanismo para disputa sociais que capacita os atores sociais a um exercício de poder graças ao seu trabalho biopolítico (Rodríguez 2012, Ross 1996). Este trabalho é o que gera bens sociais e relacionais, ao invés de apenas bens materiais, apresentando uma característica hegemônica imaterial, qualitativa, oferecendo à sociedade modos alternativos de produção, distintos dos empregos oferecidos pelas fábricas tradicionais (Foucault 2008, Lemke 2007).

Outro conceito trabalhado por Hardt e Negri é o de soberania. Segundo os autores, no final do século XIX para início do século XX, a soberania nacional aperfeiçoou-se e se transformou em soberania moderna devido à instalação dos processos de acumulação exercida pelo capitalismo industrial hegemônico vigente à época, que forneceu condiçóes materiais para essa alteração conceitual, estabelecendo uma nova relação nas estruturas de poder, com influência junto aos governantes para a manutenção de uma regulamentação capitalista de mercado. A soberania moderna se baseava na criação e manutenção de fronteiras fixas entre territórios, populaçôes, moeda, legislação, funçóes sociais, em que havia unidade de comando, limites, estabelecimento de poder e autoridade dentro de suas demarcaçóes territoriais. A soberania do fim do século XX e início do século XXI se transformou mais uma vez, amoldando-se às novas demandas do capitalismo globalizado, compondo-se por organismos internacionais e supranacionais unidos com uma lógica de dominação padronizada, com uma forma única e global de dominação, que os autores denominaram de Império. Neste ambiente, a essência de território e de povo do absolutismo foi mantida, mas com uma nova roupagem que conseguisse se adaptar aos novos processos capitalistas de produção, estabilizada por um conceito transcendental de soberania nacional, baseada numa identidade cultural, 
centrada na integração, fundada num senso de relaçôes de consanguinidade, dentro de um espaço territorial compartilhado e fortalecido pela língua comum. Com a soberania nacional esperava-se obter a independência da dominação estrangeira e a autodeterminação dos povos.

Essa dinâmica que envolve os agentes imperiais é para a manutenção do domínio sobre os habitantes dos Estados-nação e os recursos públicos que geram. Para que o Império alcance o seu objetivo, é preciso unificar os hábitos e padronizar os comportamentos, pois enquanto os membros de uma coletividade preservarem as suas singularidades manter-se-ão como multidáo, como uma relação constituinte inconclusiva, composta por diversas vontades e açóes, o que causa conflito com os governantes. Porém, o objetivo dos agentes do Império é transformar a multidão em povo, em uma síntese constituída e preparada para a soberania, visto que assim apresentam características uniformes e previsíveis, de fácil manipulação e de comportamento massificado, proporcionando uma produçáa imaterial de amplo alcance. Ao mesmo tempo em que a multidão constrói, o Império desconstrói, enquanto a multidão forma, o Império deforma, ao tempo em que a multidão gera, o Império degenera. Esse é um jogo não dialético chamado de não lugar, visto que o império se encontra em todos os lugares ao mesmo tempo. A luta social se dá no terreno biopolítico em que o Império gera a exploração do trabalho e a multidão gera o poder da vida. Desta forma, o Império organiza, enquanto a multidão é o poder que constitui como fonte onipotente e expansiva, opondo-se, assim diametralmente à soberania imperial.

A multidão age por meio da sociedade civil, que é o conjunto de organizaçôes e instituiçóes sociais, econômicas e políticas que não fazem parte do Estado, composta por indivíduos, famílias, grupos cívicos, sindicatos, partidos políticos e grupos de interesse, ao lado de todas as outras formas de associação que, através de sua alquimia política, apresenta uma expressão plural das vontades de cada um, sintetizando, de forma esclarecida, uma vontade geral de maneira unificada de maneira racional, compatível com a soberania.

Neste cenário, a biopolítica é a perspectiva em que os aspectos políticoadministrativos e demográficos atuam conjuntamente e os governos apreendem os desenvolvimentos naturais da vida e de sua reprodução, bem como as suas estruturas administrativas tais como a educação, a saúde etc. (Andreotti 2005, Cooper 2006). As técnicas em que se baseiam as práticas do biopoder iniciaram-se no poder pastoral do oriente, sendo que o pastorado cristáo apresenta primeiramente a tecnologia ocidental dos modos de governo da vida (Menezes 2012). 
Para Hardt e Negri (2012), a multidão é um modo produtivo vivo, dinâmico, que apesar de fazer parte do todo possui características autônomas, que mesmo estando dentro de um conjunto produtivo mais amplo, desenvolve movimentos próprios, únicos e independentes. É importante observar que a multidão atua diferentemente das massas, do populacho e das turbas, visto que estas últimas náo possuem componentes de singularidades, sendo sujeitos socialmente passivos, sem capacidade de agirem por si mesmos, necessitando ser conduzidos, por isso, tão suscetíveis à manipulação externa. A multidão tem um modus operandi próprio, pois é um agente ativo, internamente diferente e múltiplo da sociedade, não baseado na identidade nem da unicidade, mas naquilo que lhe é comum, que serve de base para a condução para a transformação e a liberação para a ação política no aspecto social; as ações da multidão traduzem o desafio da democracia.

Vale ressaltar que a noção de democracia ao longo do século XX foi bastante influenciado pelo estado de guerra fria em que o mundo esteve imerso nesse período. $\mathrm{Na}$ verdade, democracia pouco teve a ver com o regime de governo, mas esteve mais associado, por um lado, com a ideia de anticomunismo, representando tudo o que era definido como mundo livre, ou seja, toda forma de poder que fosse contra o totalitarismo comunista era considerada democrática. Com o fim da guerra-fria e com o advento da globalização, o conceito de democracia entrou em crise, principalmente por causa da epidemia de corrupção mundial e da insuficiência das instituições que lançaram uma cortina de penumbra sobre sua significação, visto que o mundo contemporâneo passou a exigir uma ideia distinta do que teria sido a democracia na era moderna. Outra inovação apresentada do conceito moderno de democracia é a noção de representação, que liga a multidão ao governo e, ao mesmo tempo, também a separa. A representação serve como fórmula de controle da multidáo, evitando possíveis perigos causados por uma democracia absoluta, sem limites, impregnada da radicalidade da igualdade e da liberdade, em que todos estão dotados de iguais poderes, livres para agir e escolher.

Hardt \& Negri (2012) afirmam que na era pós-moderna as concepções de dominação e de guerra tomaram um formato bastante diferente do conceito tradicional de luta armada entre naçóes, grupos de uma mesma nacionalidade ou de diferentes etnias para impor supremacia, defender seus interesses, demarcar território, com tempo e espaço claramente delimitados. A guerra contemporânea é constante e onipresente. Não possui mais tempo de duração e ocorre por todo o globo terrestre, sem delimitação de fronteiras (Hardt \& Negri 2012, Ross 1996). As motivaçóes do tempo presente podem ser ideológicas, por exemplo, em que a defesa de 
uma religião pode mobilizar conflitos armados por todo o planeta (Hardt \& Negri 2012, Cooper 2006).

A guerra transformou-se no princípio básico da organização social permanente, ficando cada vez mais difícil de distinguir a guerra da política, ou melhor, a política reduzira-se a apenas um dos recursos ou manifestaçóes da guerra. A paz civil é apenas uma transição da guerra moderna para a pós-moderna. Atualmente a guerra é a matriz central das relaçóes de poder e dominação, independente do conflito ser armado ou não (Villanova 2012, Ross 1996). Para Cooper (2006), a guerra é o exercício do regime de biopoder em que o governo visa controlar sua população ao inibir as informaçóes que lhe fornece, graças ao incentivo de uma produção da vida social que é reproduzida por ela.

Contudo, mesmo uma estratégia ilimitada como esta é passível de contradiçóes, enfrentando resistência. Por mais multidimensional que seja a dominação nunca pode ser completa e sempre encontrará oposição, pois todo poder soberano tem sempre dois lados, dependendo do consentimento ou da submissão dos dominados. Lemke (2007) indica que a passividade social é um estado temporário, pois as insurgências são o resultado da indigestão ante a governança instituída durante este. Desta forma, o poder da alienaçáo deixa de ser ilimitado, podendo ser transformado exatamente em insurgências. Ainda que o emprego comum da palavra sugira o contrário, a insurgência sempre vem primeiro, cabendo sempre à contrainsurgência reagir a ela como resposta em forma de resistência. $\mathrm{O}$ termo resistência é a palavra mais importante das dinâmicas que regem a socialização das forças (Foucault 2008), consistindo numa resposta revolucionária ao biopoder, ou seja, ao poder sobre a vida (Deleuze 2013). Nas suas discussóes sobre a análise da condução de condutas, Michel Foucault discutiu a possibilidade das pessoas exercerem uma atitude crítica que significa a recusa de ser governado (Lazzarato 2000). Assim, numa sociedade biopolítica o capital domina a vida e a vida passa a ser local de resistência (Andreotti 2005).

Muitas das principais técnicas de ativismo político revolucionário tornaram-se hoje superadas por terem sido neutralizadas por iniciativas de contrainsurgência, porém a causa mais importante de seu desaparecimento é a atual recomposição global das classes sociais, a hegemonia do trabalho imaterial e as formas de tomada de decisão baseadas em estruturas em rede, ou seja, a transformação da própria multidão. Contudo, novas formas de subversão organizada podem ser praticadas por meio de guerrilha de informação, através da ruptura do processo produtivo de circulação de dados, que são emitidos pelo poder, como forma de resistência ao modelo hegemônico capitalista contemporâneo (Guattari 1987). 


\section{PROCEDIMENTOS METODOLÓGICOS}

Tendo em vista o alinhamento teórico escolhido para a pesquisa utilizamos, como método, a Análise de Discurso Foucaultiana. Influenciado pela analítica arqueológica do pensador francês que fora desenvolvida em suas primeiras, este método tem como objetivo revelar as condiçóes de possibilidades da presença de saberes (Foucault 2014). O modo como sistematizamos as etapas que envolvem o método está baseado nos trabalhos desenvolvidos por Leão e colegas (Costa \& Leão 2011, 2012, Ianatoni \& Leão 2015a, 2015b) que, em suma, está ligado ao processo de identificação e inferência das três categorias analíticas (Tabela 1) que sustentam formaçóes discursivas.

\section{Tabela 1: Categorias analíticas (definiçóes)}

Conceito

Descrição

Trata-se de um conjunto de localizaçóes espaciais, de dependências simbólicas e de objetos materiais, cujo sentido é definido no espaço

Enunciado e no tempo por signos que fazem sentido entre si, seguindo regras

pré-determinadas que se sobrepóem em sua forma escrita.

Função

enunciativa

Regras de

formação

Formação

discursiva
Em torno de uma função enunciativa enunciados são agrupados, tendo como base as condiçóes de verdade, pelas quais símbolos e sintagmas se relacionam e são organizados.

Podem ser entendidas como condiçôes de existência que configuram, de forma singular, uma formação discursiva.

Trata-se um sistema singular que deriva de agrupamentos de enunciados e de funçôes enunciativas, cujas regras de formação configuram sua condição de existência.

Fonte: Baseado em Foucault (2014).

O processo de análise tem início com a identificação dos enunciados e, em seguida, com a identificação e análise das funções enunciativas. Nesta etapa, é possível observar a presença de mais de uma função em um enunciado, assim como a ocorrência de uma funçáo em vários enunciados. $\mathrm{Na}$ sequência do processo, temos a análise das regras de formação. A partir delas é possível estabelecer critérios para a determinação das formaçôes discursivas.

A Análise de Discurso Foucaultiana faz uso de um conjunto de dados que Foucault (2014) chamou de arquivo. Trata-se de um sistema geral de enunciados, proferidos em uma determinada época, que ilustra as práticas de discursos. Nosso arquivo foi elaborado tendo em vista representar as vozes de duas posiçóes discursivas: a oficial e a da sociedade. A primeira envolve os agentes presentes na organizaçáo do megaevento: a FIFA e 
órgãos dos poderes federal, estaduais e municipais - esses dois últimos, com base nas cidades-sede. Por sua vez, a posição discursiva da sociedade foi dividida em dois grupos: a população de forma ampla e representantes da sociedade civil, tais como representaçóes de trabalhores, Organizaçóes Náo Governamentais e quaisquer grupos organizados voltados para o debate em torno das açóes do governo na realização da Copa do Mundo.

Visando acessar tais posiçóes discursivas — principalmente relacionados a representantes do poder público e da sociedade civil —, utilizamos dados documentais coletados na internet, como matérias jornalísticas, entrevistas, posts em blogs, infográficos, vídeos e fotografias, por exemplo. Levamos em consideração materiais publicados entre janeiro de 2010 e junho de 2015, totalizando 1.465 registros para uma análise preliminar, dos quais 776 documentos foram considerados para o presente estudo. Levamos em consideraçáo para essa filtragem aqueles documentos que ilustravam direta e indiretamente tanto as posiçóes discursivas em questáo, como conflitos de interesses entre as agências envolvidas e aqui consideradas. Além disso, como forma de acesso à população, entrevistamos in loco moradores de todas as cidades-sede, em visitas realizadas entre janeiro de 2014 e abril de 2016; no processo, foram realizadas um total de 157 entrevistas, numa média acima de 13 por cidade.

\section{DESCRIÇÃO DOS RESULTADOS}

Identificamos em nossa análise a presença de duas formaçóes discursivas: a primeira está relacionada às atuaçóes da FIFA e do Governo Federal e ao modo a tais açóes foram promovidas, justificadas e tratadas por esses agentes - no que se refere tanto às próprias açôes quanto as do outro; a segunda trata, por sua vez, da reação da sociedade brasileira frente aos impactos da realizaçáo da Copa do Mundo em suas vidas, como também em relação às posturas dos agentes envolvidos na organização do megaevento. Vamos descrevê-las nas subseçóes a seguir e, para tal fim, apresentamos os enunciados, as funçóes enunciativas e as regras de formação relacionados a cada formação e, visando ilustrar esses elementos, fizemos uso de exemplo retirados de nosso arquivo de análise.

\section{Propaganda oficial}

Tendo como base o posição discursiva oficial, a primeira formação discursiva é constituída por duas regras de formaçáo, relacionada a quatro funçóes enunciativas e com quatro enunciados, que se relacionam entre si, conforme mostra a Figura 1; as definiçóes dos elementos de cada categoria são definidas no Tabela 2 . 
Figura 1: Mapa de relaçóes entre os elementos constitutivos da primeira formação discursiva

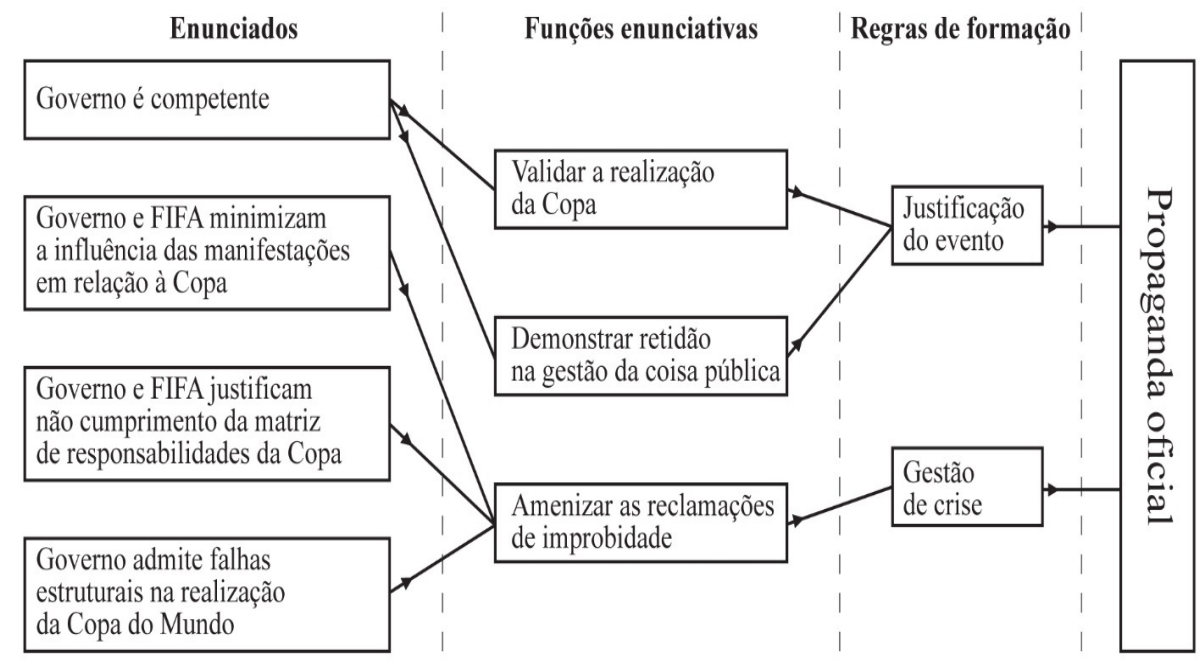

Fonte: Elaboração própria.

A relação entre tais elementos constitutivos é apresentada de tal maneira que podemos reconhecer a presença de dois feixes de relação que tem, como base, as duas regras de formação. A primeira regra de formação justificação do evento - evidencia a preocupação por parte do Goveno Federal e da FIFA de obter a aprovação, por parte da sociedade brasileira, das ações e caminhos adotados durante a organização do megaevento; para isso, foram apontadas como justificativas os legados deixados para a população. A regra de formação está ancorada nas funções que revelam não somente a preocupação da legitimação, mas também a necessidade de persuadir a opiniâo pública e de demonstrar o protagonismo e a integridade do governo brasileiro na organizaçáo da Copa do Mundo. 


\section{Tabela 2: Descriçôes dos elementos constitutivos da primeira formação discursiva}

Enunciados

Governo admite

falhas estruturais na realização da Copa do Mundo

Governo é competente

Governo e FIFA justificam não cumprimento da matriz de responsabilidades da Copa

Governo e FIFA minimizam a influência das manifestaçóes para a Copa

Funções enunciativas

Amenizar as reclamaçóes de improbidade

Demonstrar retidão na gestáo da coisa pública

Validar a realização da Copa

Regras de formação

Gestão da crise

Justificação do evento
Define-se a partir da identificação da sociedade de problemas na composiçáo de uma estrutura para a realizaçáo da Copa do Mundo de 2014 no Brasil, em que o governo teve que explicar ou justificar os motivos de náo ter conseguido alcançar os objetivos, seja na formaçáo de mão de obra, na montagem de uma base energética para suportar as demandas durante o evento ou na estruturação turística.

Publicização do governo acerca de suas ações para demonstrar que acertou ao trazer a Copa do Mundo de 2014 para o Brasil e que estava preparado para realizá-la. Tende a mostrar a sua eficiência na gestão, organização, transparência e fiscalização do megaevento, bem como das obras úteis para a população, acordadas na matriz de responsabilidades da FIFA, que inclui, além dos estádios, a reforma e ampliação de aeroportos, construçóes de mobilidade urbana e investimento em transporte público, sem utilização de dinheiro público federal.

Reforço da existência da parceria entre os representantes do Governo Federal e da FIFA, seja através de elogios mútuos, de defesa do outro, de açóes que um toma para o benefício de seu parceiro, com o intuito de apresentar à opiniáo pública explicaçóes para as situaçóes de atrasos ou improvisos para a estruturaçáo do megaevento.

Reflete um esforço, tanto da FIFA quanto do Governo, em reconhecer a legitimidade das manifestaçôes, mas, por outro lado, tentar demonstrar que as insatisfaçōes apresentadas através das manifestações populares de junho de 2013 não foram contra a realização do megaevento no Brasil e, que apesar de toda a revolta, os brasileiros estão apoiando a Copa do Mundo de 2014 no país e náo pretendem impedir sua realizaçáo.

Justificativas à sociedade brasileira dos problemas encontrados. Por meio de declaraçóes que demonstrem que a insatisfação popular não se deu com o intuito de protestar contra irregularidades do megaevento, mas para reclamar contra as políticas públicas do país.

Exposição para a opinião pública o trabalho sério do governo para a realizaçáo do evento que traria desenvolvimento para a populaçáo e crescimento para o Brasil, mostrando que a organizaçáo do evento transcendeu o caráter desportivo, tendo implicaçóes sobre aspectos sociais econômicos e políticos.

Argumentos baseados nos investimentos de cunho macroestruturais, que justificassem a realizaçáo do megaevento no Brasil em 2014.

Demonstração de preocupação e esforço, tanto do governo quanto da

FIFA, em combater as críticas, buscando comprovar que a realização da Copa do Mundo do Brasil é um evento responsável e benéfico para o país, apresentando por meio de critérios técnicos e prognóstico de cenários que com eficiência administrativa o megaevento pode trazer resultados positivos para todas as partes, empresa, governo, empresários e população.

Busca dos organizadores pela aprovação popular da Copa do Mundo, ao demonstrar que o evento foi realizado de forma ética e deixou um legado para o Brasil, que náo se limita às esferas estrutural e econômica, mas também aponta para questóes sociais e culturais.

Fonte: Elaboração própria. 
A situação descrita a seguir pode ilustrar o feixe de relação em torno dessa regra de formaçáo. O Ministro dos Esportes da época, Aldo Rebelo, afirmou que o Brasil receberia um grande número de turistas devido à grande curiosidade dos estrangeiros em nossa miscigenação e por sermos um dos principais países que ajudaram a tornar o futebol um esporte conhecido e praticado no mundo todo. Em seu pronunciamento oficial, na reunião de balanço sobre a Copa das Confederaçóes, o ministro declarou:

Superamos desafios em diversas áreas e podemos afirmar, agora, que em 2014 estaremos prontos para sediar, pela segunda vez após 1950, uma Copa do Mundo maravilhosa. A cooperação entre o COL, a CBF e o Governo Federal vem sendo feita sem nenhum tipo de problema. As melhorias em diversos pontos da infraestrutura irão beneficiar toda a população brasileira, criando um legado sustentável. Queremos organizar uma festa do futebol capaz de superar as expectativas da comunidade internacional e de nos apresentar como uma nação moderna e aberta (http://pt.m.FIFA.com/confederationscup/news/ newsid=2118347/inde-x.html [26-06-2013]).

A declaração do ministro de Estado parece se dividir em quatro momentos para responder a quatro tipos de criticas diferentes: No primeiro, ele tende a reforçar a defesa contra as acusaçóes de que o Brasil náo teria a competência suficiente para organizar um evento de tamanha monta. No segundo, ele parece querer dar por encerrado as intrigas e desentendimentos que ocorreram entre os dirigentes da FIFA e do governo. No terceiro momento, ele sugere se defender das acusaçóes que o governo recebeu de associação com a FIFA para beneficiar a entidade e seus patrocinadores, afirmando que a Copa é boa para o país. E, por último, observamos que o ministro sugere um recado diplomático para os outros países, tentando inserir o Brasil entre as grandes naçóes desenvolvidas do mundo.

Assim, esta trilha empírica demonstra os esforços que o governo fez para convencer a opiniáo pública que o evento é um anseio popular e que a Copa do Mundo seria um espetáculo grandioso tanto na festa quanto nos benefícios que traria ao país. Além, disso, tanto o governo quanto a FIFA se esforçaram para demonstrar o quanto eles estáo empenhados em desenvolver o Brasil, administrando de forma séria os recursos públicos.

A situação que decrevemos a seguir ilustra a mesma regra, porém mostrando a ideia de probidade do Governo Federal na organização do megaevento. Uma das afirmaçóes que foram repetidamente declaradas pelo governo é que o Governo Federal acertou ao trazer a Copa para o Brasil, pois geraria emprego, renda e propaganda positiva do país no exterior. $\mathrm{O}$ governo ressalta que a Copa das Confederaçóes, realizada no Brasil em 
junho de 2013, gerou com o turismo estrangeiro cerca de $\mathrm{R} \$ 740.000 .000$ para o país, além de mais de 100 mil brasileiros que viajaram pelo país no período. O Presidente do Instituto Brasileiro de Turismo (EMBRATUR), Flávio Dino, afirmou que:

Esses dados mostram que "a aposta estratégica do país" em sediar o evento está correta. [...] a Copa das Confederaçôes obteve êxito na sua organizaçáo. [...] Temos certeza que vamos atingir a meta de turistas estrangeiros no Brasil no ano que vem. A expectativa é a de que recebamos 600 mil estrangeiros e que sejam reunidos três milhóes de brasileiros (http://www.ebc.com.br/'-noticias/brasil/2013/07/ presidente-da-embratur-diz-que-manifestacoes-nao-prejudic-aramturismo [16-07-2013]).

Esta declaração emitida pelo integrante do governo parece ter a intenção de defender o governo das críticas da opinião pública acerca das acusaçóes de que a Copa tem finalidade apenas mercantil. O otimismo do gestor público sugere uma tentativa de estimular a população brasileira a apoiar o evento e, com isso, o governo se fortalecer politicamente.

A regra de formação gestão da crise traz à tona os esforços que o Governo Federal e a FIFA fizeram que rebater (ou atenuar) as críticas sofridas em torno da realização da Copa do Mundo, de forma que as acusaçóes acerca de ações desonestas envolvendo a atuação dos agentes fossem atenuadas. Essa regra se mostra presente naqueles enunciados que revelam tanto o menosprezo acerca das manifestações ocorridas contra a Copa do Mundo quanto as justificativas dadas sobre o não cumprimento de açóes previstas por parte da FIFA e do governo, assim como o reconhecimento das falhas cometidas pelo último.

O exemplo a seguir ilustra a ideia de que a posição tomada por esses agentes de que os manifestantes não estão contra a Copa expressam a ideia de que as investidas da sociedade em protesto nas ruas são por melhores condições sociais como saúde, educação, segurança e mobilidade urbana, mas não são contra a decisão de se trazer o megaevento para o Brasil. Aldo Rebelo afirmou veementemente que "as manifestações não são contra o torneio, nem tem o objetivo de impedir a realização das partidas". [Para o ministro] "houve pessoas que tentaram relacionar as manifestaçóes com a Copa do Mundo da FIFA, mas acredito que elas começaram por problemas internos, questóes de transporte, saúde e educação" (http:// www.copa2014.gov.br/pt-br/noticia/joseph-blatter-afirma-que-esta-e-amelhor-cop-a-das-confederacoes-ja-organizada-pela-FIFA?language $=e s$ [02-07-2013]). 
As declaraçôes do representante do governo parecem querer defender o parceiro comercial do país, desvirtuando a motivação das manifestaçóes populares sobre os efeitos da Copa do Mundo para os problemas que os governantes já estáo habituados a responder. O posiçáo discursiva do governo, ao afirmar que as reclamaçôes populares são sobre os problemas sociais, sugere uma intenção de não debater com a sociedade os problemas aliados com o megaevento, mas diluir as reivindicaçóes nas questóes já conhecidas e reduzir os impactos de temas como corrupção e gastos excessivos e desnecessários.

Em outra situação, observamos que a FIFA minimiza atrasos nas obras, tentando passar à população a segurança de que o governo iria concluir todas as construçôes essenciais para a realização da Copa do Mundo em tempo hábil para o início do torneio. Como exemplo, Valcke, secretáriogeral da FIFA, faz elogios a estádio, mesmo este não estando ainda com sua construção concluída:

Muito trabalho foi feito desde a última visita que fizemos a Porto Alegre. Não há preocupação em relação ao estádio. Está na fase de acabamentos. São os últimos retoques. O bom é que há muito espaço no entorno do estádio. Há todo o espaço necessário para o que precisamos. Depois de pronto, será utilizado pelo Internacional. Além disso, o acesso é fácil. Tudo isso ficará como legado para a cidade e para o clube. Porto Alegre é uma cidade muito especial para FIFA, pois a população apoia a Copa de uma forma muito elevada (http://noticias.bol.uol.com.br/ultimas-noticias/esporte/2013/10/07/ jerome-valcke-elogia-e-volucao-da-reforma-e-obras-do-entorno-dobeira-rio.htm [02-11-2013].

O pronunciamento do executivo da FIFA demonstra um esforço em citar alguns pontos positivos em uma obra atrasada, em que muito pouco havia para se elogiar, visto que até espaço vazio foi enaltecido. Esta declaração sugere um disfarce da insatisfação da FIFA com os processos de construção dos estádios, que, porém, não poderiam ser expostos naquele momento, para não comprometer a relação de parceria e, consequentemente, $\mathrm{o}$ sucesso do evento.

\section{QUEIXA POPULAR}

A segunda formação discursiva está baseada na posição discursiva da sociedade e é embasada em três regras de formação, quatro funçóes enunciativas e quatro anunciados. A presença e a relação entre esses elementos (Figura 2) revelam a ideia a postura da sociedade brasileira 
frente às açôes do Governo Federal e da FIFA durante a organização da Copa do Mundo. Na Tabela 3 apresentamos as definiçóes dessas categorias empiricamente evidenciadas.

Figura 2: Mapa de relaçôes entre elementos constitutivos da segunda formação discursiva

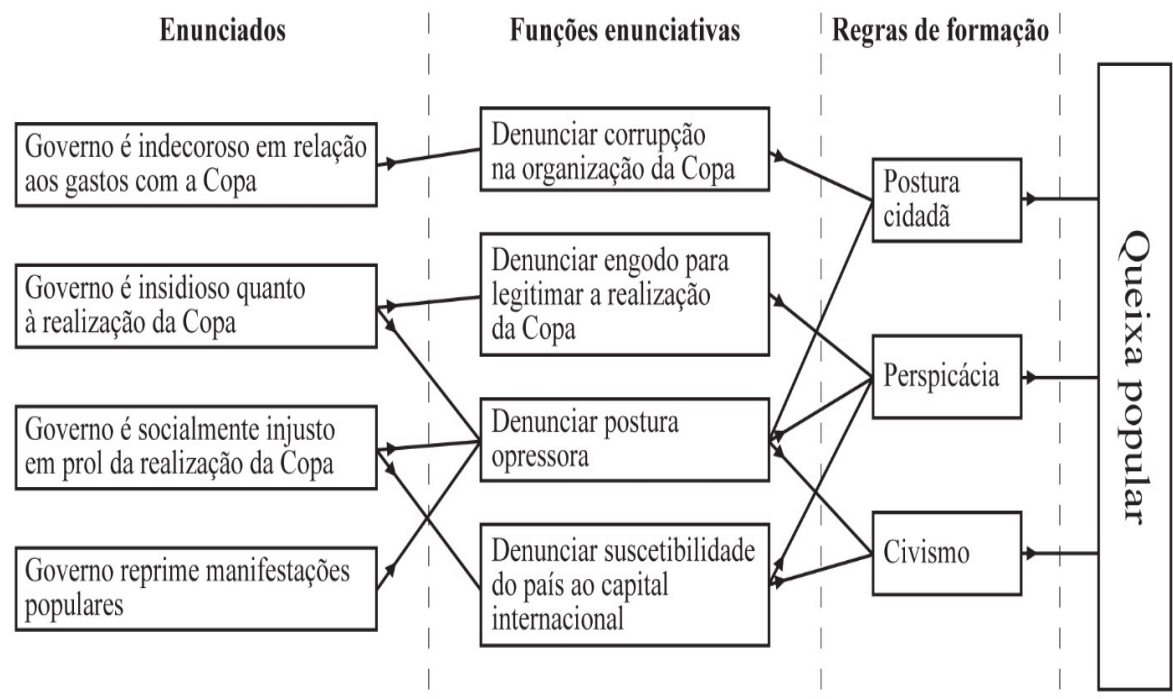

Fonte: Elaboração própria. 


\section{Tabela 3: Descriçóes dos elementos constitutivos da segunda formação discursiva}

Enunciados

\author{
Governo é insidioso \\ quanto à realizaçáo da \\ Copa
}

Governo é indecoroso em relação aos gastos com a Copa
Governo é socialmente injusto em prol da realizaçáo da Copa

Governo reprime manifestações populares

Funçóes enunciativas

Denunciar corrupção na organização da Copa

Denunciar a suscetibilidade do país ao capital internacional

Denunciar engodo para legitimar a realização da Copa

Denunciar postura opressora

Regras de formação

Postura cidadá

Civismo

Perspicácia
Define-se pelas camuflagens ou manipulação nos dados, fatos e números da Copa do Mundo diante da opinião pública, através de argumentações contraditórias, informaçóes inverídicas e minimização de situaçóes graves referentes às obras do megaevento, açóes de grande impacto para as comunidades sem antes discutir com a populaçáo e suas consequências para a sociedade brasileira.

Define-se pelas açóes de desonestidade do governo frente às açóes para a realizaçáo da Copa do Mundo de 2014 no Brasil, visto não ter entregado as obras que prometeu até a realizaçáo do evento, ter sido conivente com as situaçôes de corrupção envolvendo os processos da Copa, ter desperdiçado dinheiro público nas obras, ter investido em construçóes inócuas e por ter financiado as obras de interesse privado com dinheiro público.

Define-se pela insatisfação e revolta por parte da sociedade brasileira, devido às injustiças promovidas pelo governo, que tem desrespeitado a cultura no país e prejudicado a populaçáo mais carente, o que provocou descontentamento e motivou os diversos setores sociais a irem às ruas protestar contra o megaevento.

As manifestaçóes que ocorreram em junho de 2013 foi um fato inédito no Brasil. Não pelo levante popular, pois o Brasil tem uma extensa história de lutas e conquistas populares através de seus atos de rua, mas por sua característica de ter sido um movimento acéfalo, sem liderança definida, não havia uma reinvindicação única, nem um conjunto de solicitaçóes determinado. $\mathrm{O}$ clamor foi amplo, onde todas as inquietaçóes do povo brasileiro transbordaram pelas ruas. Diante desse fenômeno novo, sem líder, sindicato ou partido com quem negociar, náo houve como conter

a multidáo a náo ser pela opressão e, para isso, o governo teve que se aparelhar adequadamente e reprimir as manifestaçóes com violência.
Demonstração de insatisfação da sociedade brasileira com os atos de improbidade apresentados pelos representantes do governo.

Demonstração da vulnerabilidade do país diante das exigências do capital internacional.

Exposição à opiniấo pública das verdadeiras intençóes da FIFA, que são as de alcançar o máximo de ganho com todos os custos bancados com o dinheiro público, sem arcar com nenhuma responsabilização.

Demonstração das açôes de imposição de políticas de governo consideradas pouco democráticas.

Revolta acerca das denúncias de uso irresponsável de recursos públicos e das suspeitas de corrupçáo envolvendo agentes públicos e privados nos preparativos do país para a Copa.

Indignaçáo frente à demonstração de subserviência por parte dos órgãos públicos diante de exigências da FIFA.

Reaçóes populares de conscientização contrárias às tentativas dos agentes organizadores da Copa do Mundo de manipular a opinião pública, de modo a criar um cenário positivo de aprovaçáo das açóes tomadas na realização do megaevento no país.

Fonte: Elaboração própria. 
A regra de formação postura cidadã está ancorada por um feixe de relaçôes que revela denúncias da sociedade acerca da postura desonesta do Governo Federal durante a organizaçáo e realização do Copa do Mundo no país, seja revelando promessas que não foram cumpridas ou obras que não foram terminadas de forma adequada, por exemplo. Esse feixe de relaçóes traz à tona algumas questóes ligadas à má gestâo do dinheiro público, como a verificação de desvio de verbas pelos agentes que deveriam ser os seus defensores. Um morador de Manaus afirma que "o país vem sendo roubado e a Copa representa isso; fizeram um mise-en-scène em relação às obras da Copa, mas no final o dinheiro foi embolsado pelos políticos. Não gosto nem de passar perto da Arena [Amazonas], que fico revoltado". $\mathrm{O}$ relato revela a indignação de um cidadão com as práticas frequentes de corrupçáo exercida pelos governantes.

A ideia de que o governo desperdiça dinheiro público nas obras da Copa se mostra presente neste feixe de relaçóes. $\mathrm{O}$ trecho a seguir evidencia a revolta de um morador da cidade de Natal, em relaçáo à construção da Arena das Dunas e à infra-estrutura viária da cidade:

[...] não vejo melhoria nenhuma. Sinceramente. Eu vejo um elefante branco ali, crescendo, [gerando] uma dívida de não sei quantos bilhôes que os natalenses e o pessoal do Rio Grande do Norte vão pagar. E sem melhorias... Não vejo melhorias nas estradas, não vejo melhorias nas ruas; vejo muita maquiagem [que resulta n] uma imobilidade urbana, como eu costumo chamar.

O exemplo evidencia o descaso com os recursos públicos, denunciando que o critério de economicidade parece não ser considerado, mas sim a possibilidade de gerenciar uma obra mais cara. Sobre a mesma obra, no dia da inauguração da nova arena, com a presença da presidente Dilma Roussef, manifestantes protestaram em frente ao estádio, interditando uma das principais avenidas da capital potiguar — em ação presenciada in loco por um dos autores (vide Figura. 3) - contra o gasto de dinheiro público destinado àquela edificação. As principais reclamaçóes dirigiam-se à precariedade na prestaçáo de serviços essenciais na cidade, em virtude de falta de verba, que não teria faltado para a construção da Arena das Dunas, e do fato das próprias obras de mobilidade previstas para a cidade na Matriz de Responsabilidades da Copa do Mundo encontrarem-se paradas, num entendimento de que haviam sido preteridas em prol do estádio. 
Figura 3: Manifestação em frente à Arena das Dunas em sua inauguração

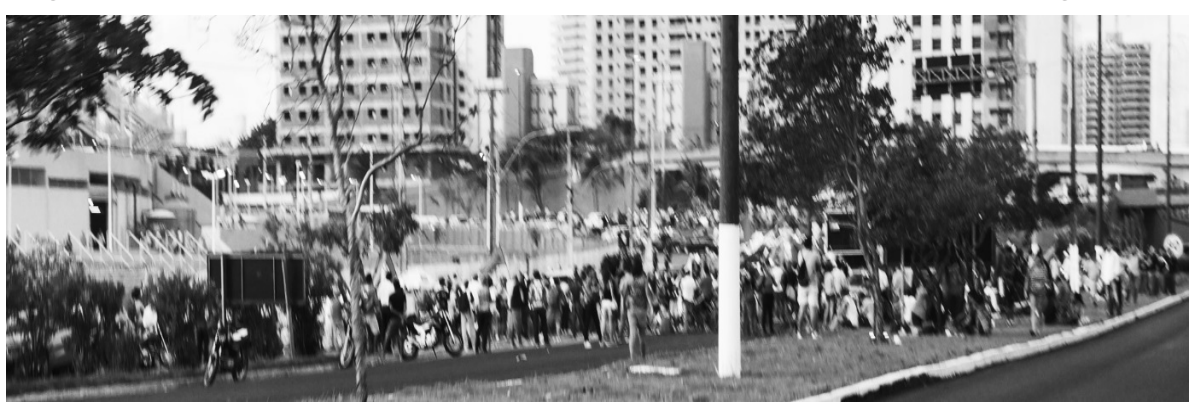

Fonte: fotografia produzida por um dos autores.

O feixe de relaçôes que se mostra presente na regra de formação perspicácia revela a preocupação da sociedade com as tentativas do governo em ludibriar a opinião páblica, no que diz respeito à justificativa das açôes assumidas ao longo da preparação do país para a Copa do Mundo, além da postura ditatorial do governo e da fragilidade do Estado brasileiro.

O primeiro exemplo que apresentamos para ilustrar essa regra de formação trata da ideia de que o governo se contradiz ao justificar os gastos com a Copa. Sobre o assunto, a Agência Pública, ONG que realiza reportagens e jornalismo investigativo, fez a seguinte denúncia:

A dívida pública com a Copa só começou a ser admitida recentemente pelo governo federal, que mantinha um discurso bem diferente. "Não haverá um centavo de dinheiro público para os estádios da Copa", falou o ministro do Esporte, Orlando Silva, em 2007. As declaraçóes oficiais mudaram este ano. Recentemente, a presidenta Dilma Rousseff disse ao jornal português Público que nem "meio estádio" sairia sem dinheiro público. O secretário-geral da Presidência da República, Gilberto Carvalho, deu uma explicação semelhante em entrevista ao UOL. "Havia uma pretensão, uma expectativa de que pudéssemos mobilizar a iniciativa privada para que ela desse conta [dos investimentos em estádios], [...] [mas] houve uma contradição entre o que se esperava e a realidade", afirmou (http://apublica.org/2014/06/tem-dinheiro-publico-sim-senhor/ [10-06-2014]).

A reportagem acima sugere que o governo brasileiro utilizou intencionalmente o argumento de que a Copa do Mundo seria realizada com recursos privados para enganar a população e atrair a simpatia da opiniáo pública, mesmo sabendo que isso não aconteceria e que o Estado teria que injetar recursos volumosos do erário para a realização do megaevento. 
Por sua vez, os feixes relacionados à regra de formação civismo denunciam náo só postura antidemocrática do governo em suas políticas e açóes e a fraqueza institucional do Estado; tais pontos seriam reflexos da subserviência do Governo Federal em relação aos interesses da FIFA. Esses elementos são revelados nos enunciados que tratam da falta de confiança da população acerca das açóes do governo.

Os exemplos a seguir ilustram esse feixe de relaçôes. Em Cuiabá, vários entrevistados destacaram o abandono das obras de infraestrutura do BLT (Veículo Leve sobre Pneus), que não ficaram prontas antes da Copa do Mundo e, depois do evento, foram suspensas, assim como o fato da Arena Pantanal ter sido inaugurada antes de ter suas obras serem finalizadas, o que também não aconteceu depois do mundial. $\mathrm{Na}$ visão dos cidadãos entrevistados que destacaram esses aspectos, tais obras teriam desconsiderado as necessidades prioritárias da cidade e servido apenas aos interesses de grandes empresas e de políticos corruptos. Isto evidencia a descrença da sociedade brasileira nas promessas feitas pelo governo acerca do desenvolvimento sustentável e da aceleraçáo do crescimento que a Copa do Mundo poderia trazer ao Brasil e aponta para o entendimento de que o governo não tem como prioridade as obras que possam dar conforto e mobilidade para o seus cidadãos de forma perene, mas as açóes imediatistas que beneficiem a iniciativa privada.

Outro exemplo gira em torno da denúncia de que o governo remove comunidades por causa da Copa, para realizar obras de mobilidade urbana e construção de estádios de futebol em benefício do megaevento, bem como para valorizar as propriedades da população mais abastada e retirar moradores de baixa renda de áreas que se tornarão valorizadas pelas obras com intuito de especulação imobiliária. Giselle Tanaka - representante da Articulaçáo Nacional dos Comitês Populares da Copa (ANCOP) denunciou no Conselho de Direitos Humanos da Organização das Naçóes Unidas (ONU), em Genebra, diversos atos de violaçôes de direitos, remoçôes forçadas e pressão por parte da FIFA e COI, que estão ocorrendo no Brasil por conta dos megaeventos de 2014 e 2016:

A realização destes eventos esportivos [Copa e Olimpíadas] no Brasil poderia ter criado a possibilidade de viabilizar significativos investimentos sociais e na infraestrutura [...] porém, os altos investimentos dispendidos para sediar os megaeventos vêm aprofundando a desigualdade social e as violaçóes de direitos no país. Isto parece ser um tema comum relacionado aos megaeventos e megaprojetos: servir ao lucro de uns e causar prejuízo a milhóes (http://apublica.org/2013/03/comites-populares-denunciam- 
remocoes-forcadas-na-o-nu/ [12-09-2013]).

A declaraçáo da representante de um dos setores da sociedade civil organizada na ONU parece reconhecer que um evento de tamanha magnitude como a Copa do Mundo seria benéfico para o Brasil. Contudo, o que parece ter acontecido foi a criação de uma grande oportunidade para os detentores das grandes corporaçóes e do capital internacional, em conluio com os governantes brasileiros, de se locupletarem do erário público às custas, e em detrimento, dos mais necessitados.

Nos dois exemplos acima podemos observar a ação biopolítica do Império agindo sobre o conjunto de processos populacionais com o objetivo de regulação e modificação da vida, buscando obter o controle das ações humanas em benefício do capital privado (Duarte 2006, Passos 2008).

\section{CONSIDERAÇÓES FINAIS}

Nossos achados evidenciam que as duas vozes observadas - as posiçōes discursivas oficial e da sociedade brasileira - representam práticas antagônicas. Isto porque enquanto uma delas ilustra uma posição de legitimação da organização e realização da Copa no Brasil, a outra embasa denúncias a respeito de práticas corruptas, opressoras e submissas do governo. Este conflito de interesses atua sobre uma tentativa de controle sobre a opinião pública que, por sua vez, demonstra resistência a esta ação. $\mathrm{Na}$ primeira formação discursiva, as açóes dos organizadores da Copa do Mundo no país buscam legitimar o megaevento e o papel do governo e amenizar críticas feitas acerca da Copa; temos, assim ilustrada, a manifestação de biopoder e a autoridade para o exercício da biopolítica dentro do país, uma vez que tais ações agem sobre a população, de modo a produzir neste corpo coletivo um consenso de que a realização da Copa do Mundo representa o desenvolvimento do país. E, nesse cenário, a presença da FIFA e sua influência sobre as decisôes governamentais representa o modelo universal econômico que sustenta as açóes biopolíticas.

Ao aceitar que a FIFA, como organismo característico do capital imperial, ocupasse o território brasileiro, o governo aceitou compartilhar com a entidade sua soberania, com o objetivo de adaptar-se às suas exigências, tomando decisóes que, por muitas vezes, foram de encontro aos interesses da população brasileira. Isto provocou na populaçáo uma reação política, que evidencia uma crise da democracia no país, uma vez que a população demonstra não se sentir representada pelo governo. 
A segunda formação discursiva ilustra a reação da sociedade enquanto multidão: as denúncias revelam posições singulares que, agrupadas como tal voz, mostram que as reais demandas sociais não estáo alinhadas com as justificativas apontadas pelos organizadores da Copa. Essa situaçáo ilustra a presença de um coletivo de singularidades estabelecidas que busca criar resistência ao poder exercido através da soberania e da criação, por parte da primeira, de uma representaçáo padronizada de comportamentos e necessidades de um povo. A dinâmica envolvendo essas duas vozes ilustram a guerra biopolítica e revelam uma crise da democracia no país.

O presente trabalho contribui para um entendimento dos impactos tanto econômicos quanto políticos da realização de um megaevento mundial significativo, tendo em vista o papel de um importante agente mundial nas açóes governamentais de um país, bem como sobre suas consequências sociais, uma vez que traz à tona uma discussáo acerca dos efeitos das reivindicaçóes da sociedade civil nas açôes da Gestão Pública. Apresenta, assim, um diálogo com trabalhos que apontam os resultados que a realização da Copa do Mundo FIFA 2014 no Brasil teve na nação (Diniz, Ribeiro \& Palhares 2017, Nobre 2017, Reis \& Cabral 2017), introduzindo o efeito potencial do megaevento esportivo nas açóes governamentais do país e nas consequentes respostas de sua população.

Como limitação do estudo, reconhecemos que as duas posiçôes discursivas acessadas não refletem corpos homogêneos em si, uma vez que, por um lado, a sociedade é formada por diferentes camadas e grupos de interesses distintos e por vezes contraditórios, enquanto, por outro lado, os interesses da Fifa e do governo brasileiro não são idênticos e mesmo diferentes instâncias de governo podem apresentar variação em suas posturas, relacionadas, por exemplo, com as localidades e os partidos ocupantes dos cargos.

Por fim, como possíveis desdobramentos de nossa pesquisa, apontamos a possibilidade de estudos futuros sobre os impactos a longo prazo das açóes governamentais e das promessas de legados feitas durante a organização da Copa do Mundo no país, como também a realizaçáo de pesquisas que se debrucem sobre as decisóes dos agentes envolvidos e os consequentes impactos econômicos, sociais e políticos em outros megaeventos esportivos, tais como os Jogos Olímpicos do Rio de Janeiro (2016), como forma de ampliar o entendimento da mesma realidade aqui investigada, e a Copa do Mundo da Rússia (2018), que ocorrerá num contexto político-econômico semelhante ao do Brasil. 
LEÃO ET AL.

\section{AGRADECIMENTOS}

O presente trabalho só foi possível graças ao apoio do Conselho Nacional de Desenvolvimento Científico e Tecnológico (CNPq). 


\section{REFERÊNCIAS}

Abreu, A. C. D., Helou, A. R. H. A. y Fialho, F. A. P. (2013). Possibilidades Epistemológicas para a Ampliação da Teoria da Administração Pública: Uma Análise a Partir do Conceito do Novo Serviço Público. Cadernos EBAPE.BR, 11 (4), 608-620.

Amdam, R. (2014). An Integrated Planning, Learning and innovation System in the Decentralized Public Sector: A Nowergian Perspective. The Innovation Journal: The Public Sector Innovation Journal, 19 (3), $1-16$.

Andreotti, B. L. R. (2005). A Desmaterialização do Imperialismo: O Conceito de Império de Antonio Negri. Projeto História, 30 (1), 369375 .

Collier, S. y Lakoff, A. (2014). Vital Systems Security: Reflexive Biopolitics and the Government of Emergency. Theory, Culture \& Society, 4 (1), $1-33$

Cooper, M. (2006). Pre-Empting Emergence: The Biological Turn in the War on Terror. Theory, Culture and Society, 23 (4), 113-35.

Costa, F. Z. N. y Leão, A. L. M. S. (2011). Desvelamento do Limiar Discursivo de uma Marca Global em uma Cultura Local. Cadernos EBAPE.BR, 9(2), 299-332.

. (2012). Formações Discursivas de uma Marca Global num Contexto Local: Um Estudo Inspirado no Método Arqueológico de Michel Foucault. Organizaçôes \& Sociedade, 19 (62), 453-469.

Da Matta, R. (1991) O Que Faz o Brasil, Brasil? Rio de Janeiro: Rocco.

Dahl, R. (2001). Sobre a Democracia. Brasília: UnB.

Damo, A. S. y Oliven, R. G. (2013). O Brasil no Horizonte dos Megaeventos Esportivos de 2014 e 2016: Sua Cara, seus Sócios e seus Negócios. Horizontes Antropológicos, 19 (40), 19-63.

Deleuze, G. (2013). Conversações: 1972-1990. São Paulo: Editora 34.

Denhardt, R. B. (2012). Teorias da Administração Pública. São Paulo: Cengage Learning. 
Denhardt, R. B. y Denhardt, J. (2000). The New Public Service: Serving Rather than Stering. Public Administration Review. 60 (6), 549-559.

Diniz, A. M. A., Ribeiro, L. L. y Palhares, R. H. (2017) O Impacto da Realização da Copa das Confederaçóes da FIFA de 2013 e da Copa do Mundo da FIFA de 2014 na Criminalidade em Belo Horizonte. Confins, 32.

Djelic, M-L. y Sahlin-Andersson, K. (2006). Transnational Governance: Institutional Dynamics of Regulation. Cambridge: Cambridge University Press.

Fédération Internationale de Football Association (FIFA). (2013). Classic Football. Disponível em http://www.FIFA.com/classicfootball/history/index.html [04-12-2017].

Foucault, M. (2008). Nascimento da Biopolitica: Curso Dado no College de France (1978-1979). São Paulo: M. Fontes. . (2014). A Arqueologia do Saber. Rio de Janeiro: Forense Universitária.

Grellet, C. (2010). Copa 2014 e o Clubes de Futebol no Brasil. Cadernos FGV Projetos, 13 (1), 52-56.

Guattari, F. (1987). Revolução Molecular: Pulsaçôes Políticas do Desejo. São Paulo: Brasiliense.

Giesler, M. y Veresiu, E. (2014). Creating the Responsible Consumer: Moralistic Governance Regimes and Consumer Subjectivity. Journal of Consumer Research, 41 (3), 840-857.

Hardt, M. y Negri, A. (2006). Império. Rio de Janeiro: Record.

Hardt, M. y Negri, A. (2012). Multidão: Guerra e Democracia na Era do Império. Rio de Janeiro: Record.

Ianatoni, T. y Leão, A. L. M. S. (2015a). Pague e Peque: Uma Arqueologia do Discurso do Adultério Mercadorizado. Revista de Administração Contemporânea, 19 (1), 732-749. Sobre a Mercantilização do Adultério. Organizaçóes \& Sociedade, 22 


$$
\text { (1), 443-463. }
$$

Jornal do Commercio (2011). MPPE Quer Manter Proibição à Venda de bebidas Alcoólicas. 1 de Dezembro. Disponível em http://jconline. ne10.uol.com.br/canal/esportes/copa-2014/noticia-/2011/12/01/ mppe-quer-manter-proibicao-a-venda-de-bebidas-alcoolicas- 24143. php [04-12-2017].

(2012). Lei Geral da Copa Recebe Críticas por Restringir Comércio em torno dos Estádios, 29 de Janeiro. Disponível em http://jconline.ne10.uol.com.br/canal/esportes/copa-2014/ noticia/2012/01/29/lei-geral-dacopa-recebe-criticas-por-restringircomercio-em-torno-dos-estadios-30221.php [04-12-2017].

Koch, P. y Hauknes, J. (2005). On Innovation in the Public Sector - Today and Beyond. Oslo: PUBLIN.

Klumb, R. y Hoffmann, M. (2016). Inovação no Setor Público e Evolução dos Modelos de Administração Pública: O Caso do TRE-SC. Caderno Gestão Pública e Cidadania, 69 (21), 86-102.

Lazzarato, M. (2000). Du Biopouvoir à la Biopolitique. Multitudes, 1 (1). Disponível em http://www.multitudes.net/Du-biopouvoir-a-labiopolitique/ [04-12-2017].

Lemke, T. (2007). An Indigestible Meal? Foucault, Governmentality and State Theory. Distinktion. Journal of Social Theory, 8 (2), 43-64.

Medeiros, A. K. de, Crantschaninov, T. I. y Silva, F. C. da. (2013). Estudos sobre Accountability no Brasil: Meta-Análise de Periódicos Brasileiros das áreas de administração, Administração Pública, Ciência Política e Ciências Sociais. Revista de Administração Pública, 47 (3), 745-775.

Menezes, L. A. M. (2012). Michel Foucault e o Conceito de Governamentalidade. Revista Inquietude, 3 (1), 199-211.

Nicolas, M. (2013). O Choque da Copa. Disponível em http://-www. ey.com/BR/pt/Issues/Marcos_Nicolas_-_OGlobo_032013 [04-122017].

Nobre, E. (Ed.). (2017). Sports Mega-Events and Urban Legacies: The 2014 FIFA World Cup, Brazil. Cham: Palgrave Macmilan. 
Oliveira, K. y Paula, A. P. (2014). Hebert Simon e os Limites do Critério de Eficiência na Nova Administração Pública. Caderno Gestão Pública e Cidadania. 64(19), 113-126.

Osborne, S. y Brown, L. (2011). Innovation, Public Policy and Public Services Delivery in UK: The Word tha Would be King? Public Administration, 89 (4), 1335-1350.

Paula, A. (2005). Por uma Nova Gestão Pública: Limites e Potencialidades da Experiência Contemporânea. Rio de Janeiro: Editora FGV.

Reis, C. J. O. y Cabral, S. (2017). Parcerias Público-Privadas (PPP) em Megaeventos Esportivos: Um Estudo Comparativo da Provisão de Arenas Esportivas para a Copa do Mundo Fifa Brasil 2014. Revista de Administração Pública, 51 (4), 551-579.

Richard, S. y Rieu, T. (2009). Uma Abordagem Histórica para Esclarecer a Governança da Água. Em Jacobi, P. R. y Sinisgalli, P. A. (eds.), Dimensóes Político-Institucionais da Governança da Água na América Latina e Europa. (Vol II). São Paulo: Annablume.

Rodríguez, I. S. (2012). La Movilidad de los Objetos Tecnocientíficos: Un Ejemplo de Biopolítica a través de las Patentes/Technoscientific's Objets Mobility: A Biopolitical Example Through Patents. Politica y Sociedad, 49 (3), 549-570.

Ross, A. (Ed.). (1996). Science Wars. Durham: Duke University Press.

Tenório, F. G. (2005). (Re)visitando o Conceito de Gestão Social. Em Lianza, S. y Addor, F. (Eds.), Tecnologia e Desenvolvimento Social e solidário. Porto Alegre: UFRGS.

Uol. (2012). Fuleco é Escolhido como Nome da Mascote da Copa de 2014. 25 de Novembro. Disponível em http://copadomundo.uol. com.br/noticias/redacao/2012/11/25/esco-lhido-nome-do-mascoteda-copa-de-2014.htm [04-12-2017].

Villanova, L. F. M. (2012). A Nova Guerra: Uma Introdução. Revista Opinião Filosófica, 3 (2), 101-107. 
Leis, decretos, resoluçóes

Decreto de 14 de janeiro de 2010, Institui o Comitê Gestor para definir, aprovar e supervisionar as açóes previstas no Plano Estratégico das Açóes do Governo Brasileiro para a realização da Copa do Mundo FIFA 2014, e dá outras providências. Diário Oficial da União. Brasília: Presidência da República.

Lei 12.663 , de 5 de junho de 2012. Dispóe sobre as medidas relativas à Copa das Confederaçóes FIFA 2013, à Copa do Mundo FIFA 2014 e à Jornada Mundial da Juventude - 2013. Diário Oficial da Uniáo. Brasília: Presidência da República.

Resolução, de 22 de novembro de 2012. Aprova os fóruns técnicos de atuação do Governo Federal. Diário Oficial da União. Brasília: Ministério do Esporte.

Recibido: 08-11-2016

Aceptación de la versión final: 22-12-2017 